women known to be pregnant. He said that the average woman knew that if she became pregnant she should not take drugs.

Referring to the stillbirth of Mrs Downs's baby (15 December 1984, p 1683), Dr Gee asked whether the defendants were contending that the stillbirth was a result of his treatment. $\mathrm{Mr}$ Rankin made it clear that this was not part of his clients' case.

During Mr Rankin's absence with flu Dr Gee was cross examined by Charles Gray QC, leading counsel for Dr Blackwood and Dr Mitchell, the two doctors Dr Gee is suing for libel over their part in the That's Life broadcast. Mr Gray asked Dr Gee if, when Mrs Day consulted him, he had found out that she had been diagnosed as prediabetic and had been treated with oral hypoglycaemics. Dr Gee replied that a glucose tolerance test carried out in 1969 in the eighth month of pregnancy had shown a level of $115 \mathrm{mg} / 100 \mathrm{ml}$, which was not diabetic or prediabetic. Mrs Day, he added, had been put on phenformin not as an oral hypoglycaemic but to control her weight.

Counsel suggested that Mrs Day had become thyrotoxic on $\mathrm{Dr}$ Gee's treatment. He put it to Dr Gee that her pulse rates showed a declining curve from around 28 April, just before she stopped taking thyroid extract. Dr Gee pointed out that her pulse rate had gone up again on 10 June. Mr Gray suggested that the symptoms Mrs Day had complained of to Dr Blackwood were symptoms of thyrotoxicosis. Dr Gee admitted that some of them could be symptoms of thyrotoxicosis but said that they could all have a cause other than thyrotoxicosis. Most of the symptoms she allegedly complained of-for instance, palpitations, heat intolerance, and irritability - could be caused by nervous tension or an anxiety state. Hair dropping out was a symptom of hypothyroidism, and shortness of breath was not a symptom of thyrotoxicosis except where it was sufficiently long term to produce heart damage.

Dr Gee agreed that severe and prolonged thyrotoxicosis led to increased force and output of the heart and excitation of the cardiovascular system, and that the extra demand on the heart could lead to the growth of extra tissue. He also agreed that prolonged hyperthyroidism could give rise to atrial fibrillation. He agreed that with this condition a clot could form on the wall of the atrium which could break off and be expelled through the arterial system and cause death by cutting off the blood supply to the part that was blocked. But Mrs Falconer died from a large coronary thrombosis, which the literature showed was very rare with thyrotoxicosis.

\section{Results of laboratory tests}

Resuming his cross examination, Mr Rankin quoted from a letter sent to Mrs Falconer's husband by the hospital after her death: "Features of her medical history and examinations suggested thyroid overactivity, and as you are aware she had for some time been taking tablets for slimming. In fact some of these were thyroid tablets." Dr Gee insisted that Mrs Falconer's thyroid tests had shown no evidence of any thyroid abnormality. Mr Rankin pointed out that the free thyroxine index was 200 , outside the normal laboratory range. Dr Gee said the free thyroxine index was an outmoded method of calculation that was no longer used. The triiodothyronine referred to in the laboratory result was not a test of thyroid function, or was so only indirectly. The blood test had shown that there was no thyroid overactivity. Dr Gee referred to an article that he said showed that the free thyroxine index could be grossly raised in women, like Mrs Falconer, who were taking the pill.

Re-examined by his own leading counsel, Michael Beloff QC, Dr Gee said that Mrs Day's 1969 glucose tolerance test had shown that she was not diabetic. Looking at her hospital notes, it appeared that in 1970, when phenformin was prescribed, a random blood sugar test had shown a level of $70 \mathrm{mg} / 100 \mathrm{ml}$.

At the time phenformin was used mainly for weight reduction in obese non-diabetics. If it was being used as an oral hypoglycaemic it would have had to be continued, and there was nothing in Mrs Day's notes to suggest that she received phenformin over the years 1971 to 1975 . Dr Gee said that the reading of $115 \mathrm{mg} / 100 \mathrm{ml}$ at one and a half hours on Mrs Day's glucose tolerance test in 1969 would have been higher than $160 \mathrm{mg} / 100 \mathrm{ml}$ if she had been diabetic. $\mathrm{He}$ added that all Mrs Day's symptoms could have a cause other than thyrotoxicosis. The only diagnosis that fitted all the symptoms was an anxiety state.

He cited a paper from Acta Endocrinologica that gave a mean free thyroxine level of $53 \pm 8 \cdot 6$ and a mean thyroxine level of $288 \pm 53$ for thyrotoxic patients. He pointed out that Mrs Day's corresponding values were 28 and 156 respectively, and she had been having exogenous thyroid. He also cited articles showing that antibodies were apt to develop with the administration of thyroid extract, which could increase the free thyroxine levels, and that false positive increases in the free thyroxine index occurred commonly in psychiatric patients.

Looking at the graph of Mrs Day's pulse rates, which had been shown to him by Mr Gray, and continuing the graph with later recorded pulse rates up to January 1984, Dr Gee said they showed a labile pulse rate subject to variation without any obvious cause, and therefore the variation must have an emotional basis. It was impossible that even an overdose of thyroid hormones (which his treatment was not) could produce such effects over a year later.

Nor was there any evidence either in Dr Blackwood's notes or in his report back to the general practitioner that there was anything wrong with her heart. The echocardiogram and 24 hour cardiograms were normal. Reading through her notes from November 1983 until August 1984, culminating in Dr Blackwood's comment, "I think Mrs Day is slipping into quite a marked psychiatric state. She seems to have feelings of claustrophobia, depression, anxiety and probably agoraphobia," Dr Gee concluded that Mrs Day was a psychiatric case.

Mr Beloff said that the BBC was alleging that Dr Gee's treatment caused the death of Mrs White (on 4 July 1983). Dr Gee replied that he did not accept that in any measure. He reiterated his evidence that her last visit had been on 30 June. He had a cheque signed by her and dated that date, which was for the consultation and treatment. Asked to what he could attribute the intermittent palpitations of which Mrs White had complained to her general practitioner, Dr Gee replied that they could have been due to a disturbance in the conducting mechanism of the heart, a preexcitability. This could be caused by smoking, stress or alcohol.

The trial was scheduled to resume on 14 January.

This article follows on from the one published on 15 December 1984 (p 1683).

\section{Correction}

Research in general practice: pursuit of knowledge or defence of wisdom?

We regret that an error occurred in this article by Professor J G R Howie (22-29 December, p 1770). The lecture on which Professor Howie's paper was based was wrongly described. The footnote should have read: "Based on the sixth Wedgwood lecture delivered at the North Staffordshire Medical Institute, Stoke on Trent, in March 1984."

The symptoms of a 66 year old man with lifelong narcolepsy of moderate severity with hypnagogic hallucinations and cataplexy are largely controlled with $12.5 \mathrm{mg}$ of dexamphetamine daily. Recently he added clomipramine $10 \mathrm{mg}$ daily to the existing medication, and this has helped. It would have been of more help if he could take $20 \mathrm{mg}$ daily but clomipramine, even at the dose of $10 \mathrm{mg}$ daily, causes erectile failure. Is there any other preparation with the same effect as clomipramine that is less likely to cause erectile failure?

Erectile failure is largely a result of the anticholinergic effect of clomipramine, a property shared by the other tertiary amino tricyclic antidepressants such as imipramine, trimipramine, and amitriptyline. Changing to one of these alternative tricyclic drugs would probably be unhelpful. Some of the newer antidepressants such as mianserin, a tetracyclic compound, have little or no anticholinergic activity and may be less likely to cause ejaculatory failure. On the other hand, the evidence that mianserin is effective in narcolepsy is less convincing than for the tricyclic drugs, but it would be worth trying, starting with a single night time dose of $30 \mathrm{mg}$.-A RICHENS, professor of pharmacology, Cardiff. 